\title{
Rough Sets and Colonies of Artificial Ants for the Improvement of Training Sets
}

\author{
Carmen F. Rey-Benguría
}

\begin{abstract}
Improving training sets is an area of active research within I to Artificial Intelligence. In particular, it is of particular interest in supervised classification systems, where the quality of training data is crucial. This paper presents a new method for the improvement of training sets, based on approximate sets and artificial ant colonies. The experimental study carried out with international databases allows us to guarantee the quality of the new algorithm, which has a high efficiency.
\end{abstract}

Keywords : classification, artificial intelligence, data preprocessing, algorithms.

\section{INTRODUCTION}

The k Nearest Neighbor classifier is of the peak popular supervised algorithm. Nearest Neighbor, to assign the class to a new pattern, compares it. with all the patterns of the training matrix, using a distance function, and determines the $\mathrm{k}$ objects of the training matrix closest to the given object. Finally, it assigns the majority class.

In recent years, the existence of digital storage systems has increased dramatically, and the ability to create large databases has been exploited in a wide number of domains and applications [1-9]. In general, the explosion in data volumes has made it very complex to find the nearest neighbor(s) to a given object [10-15], since it needs to make a very big number of evaluations, proportional to size of the data set, and with it a high consumption of resources and time, to achieve the result [16-19].

In addition, the presence of noisy or mislabeled objects in the training matrix makes all objects near a noisy object tend to be misclassified [20-22].

One of the strategies that has been proposed to solve the aforementioned problems of the NN family is the combined or simultaneous selection of features and objects. For this purpose, various methods have been developed [23-27], among which family outstand the fusion submatrices.

The latter, despite their multiple advantages and high performance, have not been designed to handle noisy or mislabeled objects, and also incorporate very elementary fusion schemes, where the capabilities of the sub-matrices

Revised Manuscript Received on April 11, 2020.

* Correspondence Author

Carmen f. Rey Benguría*, Educational Center “José Martí,, University of Ciego de Ávila, Ciego de Ávila, Cuba. Email: carmenrb2008@gmail.com

(C) The Authors. Published by Blue Eyes Intelligence Engineering and Sciences Publication (BEIESP). This is an open access article under the CC BY-NC-ND license (http://creativecommons.org/licenses/by-nc-nd/4.0/) obtained are not fully exploited, nor optimization strategies are used [28-36].

\section{MATERIALS AND METHODS}

The combined or simultaneous selection of features and objects [24] allows in the same algorithm the selection of both features and objects, in addition to the fact that you can use all the information from the training matrix. Unlike the sequential selection, the first method that is applied has access to all the information in the training matrix, while the second one can only use the results of the first method [37-46].

Among the methods, simultaneous selection of features and objects is the fusion of sub-matrices. Methods family fusion submatrices are based on obtaining submatrices from the training matrix, casting it with the characteristics obtained by calculating typical testors and applying selection methods objects each projection. Subsequently, the submatrices joined using procedure fusion.

In more detail, submatrix fusion methods operate as follows: 1) Calculate the typical testers. The typical testors are subsets of features that have two basic properties are irreducible and combinations of features not confuse descriptions of objects of different classes. That is, a typical testor is a subset of traits with a high discriminative power. Although the calculation of typical testers is a non- polynomial problem (NP), there are efficient algorithms for their computation such as the LEX [47].

2) Project the training matrix using the features present in each testor. In this step, several sub-matrices are obtained with the same number of samples of the training matrix, and with the features present in each typical testor.

3) Apply a method of selecting objects in each projection, thus obtaining a submatrix. In this phase, the projections obtained in step 2 are reduced in the number of objects, by using a selection method.

4) Order the submatrices, following a certain criterion.

5) Merge the submatrices until a certain stop condition is met. The merged submatrix will have all the features and objects of the submatrices that gave rise to it.

It should be noted that these methods are specially designed for mixed and incomplete data. Mixed and incomplete descriptions are those in which an object is described simultaneously by numerical and categorical features, and where in some cases the value of one or more features may be unknown [48-55].

Within the methods of the family of sub-matrix fusion are SOFSA[20] and TCCS [17].

Published By:

Blue Eyes Intelligence Engineering

\& Sciences Publication

(C) Copyright: All rights reserved.

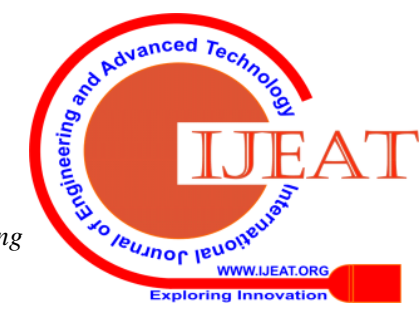


These methods, despite having good experimental performance, have some disadvantages. These include the SOFSA sometimes does not reduce or features or objects, and although the TCCS has better reductions in the number of objects, and us to the effectiveness of the classifier in the process of ordering of submatrices, also it has a reduction high features. Both methods are not designed for handling noise, and do not exploit the potential of submatrices obtained thus and fusion process followed is one go subarrays in the obtained order, until it improves classification error. This strategy leads to the realization of unnecessary mergers, which do not contribute to a decrease in error. In addition, they do not include optimization strategies in the merger process.

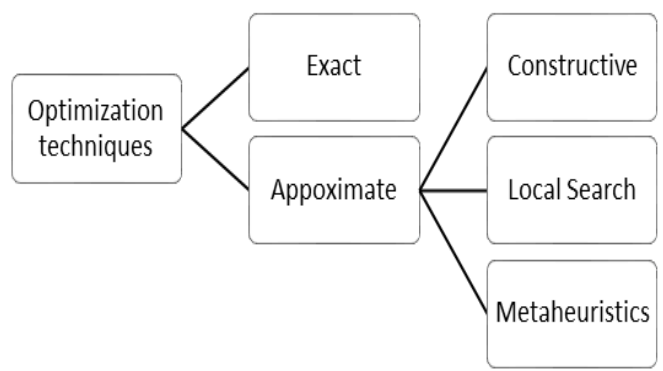

Fig. 1.Optimization techniques

In the scientific context, optimization is the process of finding the best solution for a given problem. Within the optimization techniques are the exact and approximate ones (see figure 1).

The exact optimization techniques guarantee to find the optimal solution of the problem that you want to solve, but to obtain this optimal solution the time grows exponentially with the size of the search space, and in some cases its computational cost, as well as the time to finding the solution is too high. Thus, the approximate algorithms try to solve this problem, sacrificing the guarantee of finding the optimal solution in a long time and high cost, in exchange for finding an approximate solution that approaches the optimal one in a much shorter time.

Given a set of submatrices, we want to obtain the best combination of mergers, taking as a quality criterion the error of the classifier trained with said fusion. The process of merging sub-matrices can therefore be addressed as an optimization problem, where the solution space is given by all possible mergers, and the objective function is the classification error. The initial states would be each of the sub-matrices, and the final state would be one such that its error is less than the error of the best sub-matrix.

In solving optimization problems, meta-heuristic procedures allow obtaining good solutions with a reasonable computational cost [56-58]. These methods have proven their efficiency over a significant collection of problems. Among the best-performing metaheuristic procedures are Genetic Algorithms [59], Particle Swarm Optimization [60] (PSO) and Ant Colony Optimization (ACO) [61, 62]. These last two are classified as bioinspired or artificial life and collective intelligence algorithms, since the potential of these models to solve problems is given by the cooperation between individuals in a direct or indirect way.
Specifically, in ACO metaheuristics, cooperation takes place between ants in an indirect way. The ACO model has shown high applicability to solve different discrete optimization problems, with excellent results, since its emergence it has represented a very good tool to solve combinatorial optimization problems. This model is based on using the behavior of natural ant colonies, which minimize the path between their nest and any food source.

Rough Sets have established to be operative for data analysis, with machine learning being one of the work areas where it has stimulated the greatest interest. The Rough Sets Theory (RST) was introduced by Z. Pawlak in 1982. The viewpoint of the approximate sets is based on approximating any concept, a hard subset of the domain such as, for example, a class in a problem of supervised classification, by a pair of exact sets, called lower approximation and higher approximation of the concept.

In the case of the Approximate Sets Theory, the basic information structure is the Information System. Be a set of characteristics and a non-empty set $U$ called universe of samples described using the characteristics in $A$; the pair $(U, A)$ is called the Information System. If a new feature called decision is added to each element of $U$, indicating the decision taken in that state or situation (class to which the object belongs), then a Decision System $(U$, $\{A \cup\{\propto\}\})$, is obtained, where $\propto \notin A$.

The decision attribute $K_{i}=\left\{o \in U, \alpha_{i}(o)=1\right\}$ induces a partition of the universe $U$ of objects. Be the sets $K_{i}=\left\{o \in U_{0}, \alpha_{i}(o)=1\right\}$, then $K_{1}, \ldots, K_{l}$ is a collection of equivalence classes. It is said that an attribute $A_{i} \in A$ separates one object $\boldsymbol{x}$ from another $\boldsymbol{y}$, and it is written distinguishes $\left(A_{i}, x, y\right)$, if is fulfilled $\chi_{i}(x) \neq \chi_{i}(y)$, although in a simplified way it is defined as follows $x(i) \neq y(i)$, where $x(i)$ denotes the value of attribute $i$ in object $x$.A binary inseparability relationship $R$, defines the pairs of inseparable samples by the relationship:

$$
R=\left\{(\mathrm{x}, \mathrm{y}) \in U \mathrm{x} U: \mathrm{x}(\mathrm{i})=\mathrm{y}(\mathrm{i}) \forall A_{i} \in B\right\}
$$

Let $\mathrm{DS}=(\mathrm{U}, \mathrm{A} \cup\{\alpha\})$ be a decision system, and $B \subseteq A$ and $X \subseteq U, B$ defines an equivalence relation and the subset $X$ is a concept in the universe $U . X$ can be approximated by the approximations $B$-lower and $B$-superior, denoted by $B{ }_{*} X$ and $B{ }^{*} X$, respectively, and defined by the expressions 2 and 3 respectively.

$$
\begin{aligned}
& \operatorname{INF}(X)=B_{*} X=\left\{\mathrm{x} \in U:[\mathrm{x}]_{B} \subseteq X\right\} \\
& \operatorname{SUP}(X)=B^{*} X=\left\{\mathrm{x} \in U:[\mathrm{x}]_{B} \cap X \neq \phi\right\}
\end{aligned}
$$

Where $[\mathrm{x}]_{B}$ denotes the class of $\boldsymbol{x}$ according to the relationship of inseparability $B$.

In [63] it is analyzed how in the case of mixed data four different alternatives can be adopted: 
(i) analyze the numerical attributes separately from the non-numerical attributes and then make a decision on the basis of the partial results obtained; ( ii ) discretize the numerical attributes;(iii) encode non-numerical attributes considering codes as numbers and proceeding with them as if they were; (iv ) work with mixed descriptions. Different insufficiencies of the first three alternatives are studied, and it is based on how the last alternative is the most appropriate.

In this case it is necessary to use other types of inseparability relationships between the objects of the $U$ universe [64]. By replacing the equivalence relationship with a weaker binary relationship, that is, where some of the properties (reflexibity, symmetry or transitivity) are not met, an extension of the classic RST approach is obtained. The extension of the classic approach RST is obtained by modifying the concept of inseparability objects so that similar objects are grouped not identical in the same class as a similarity $R$. Similarity relationships do not induce a partition of the universe $U$, but generate similarity classes for any object $\mathrm{x} \in U$. The similarity class of $\mathrm{x}$, according to the similarity relationship $R$ is denoted by $R(\mathrm{x})$.

$$
R(x)=\{y \in U: y R x\}
$$

This is read as "the set of objects of the universe $U$ that are similar to the object $\boldsymbol{x}$ according to the relation $R$ ". An example is the case of tolerance relationships, where the relationship $R \subseteq U \mathrm{x} U$ is reflexive ( $\mathrm{x} R \mathrm{x}$ ) for any $\mathrm{x} \in U$ and symmetric ( $\mathrm{x} R \mathrm{y} \Rightarrow \mathrm{y} R \mathrm{x}$ ) for any pair $\mathrm{x}, \mathrm{y} \in U$.

Different researchers have developed studies on RST in the case of approach spaces that are coverings; some of them oriented to build a generalization of the RST based on coverings. These extensions of the RST have also been used for the selection of objects. However, the potentialities of optimization techniques and approximate sets in the combined selection of features and objects have not been exploited.

That is why this work introduces a new submatrix fusion scheme, based on the use of Artificial Ants Colonies (ACO) metaheuristics for the improvement of $\mathrm{NN}$ classifiers. The proposed new scheme, called FIS_ACO, was experimentally tested in repository databases, with results superior to those of other fusion schemes. This scheme includes the use of the lower approximations of the Approximate Sets of Maximum Similarity for the pre-processing of the data and an optimization.

\section{RESULTS AND DISCUSSION}

As mentioned earlier, ACO algorithms are iterative processes. In each repetition a colony is "launched" and each ant builds a solution to the problem (figure 2).

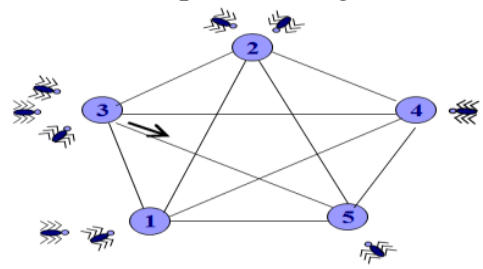

Fig. 2.Simulated antes in a graph
The modeling of the graph is given with the following structure, there is a training matrix, which gives way to sub-matrices calculated with typical testers and applying a method of object selection. Each submatrix will be part of the vertices of the graph (figure 3 ).

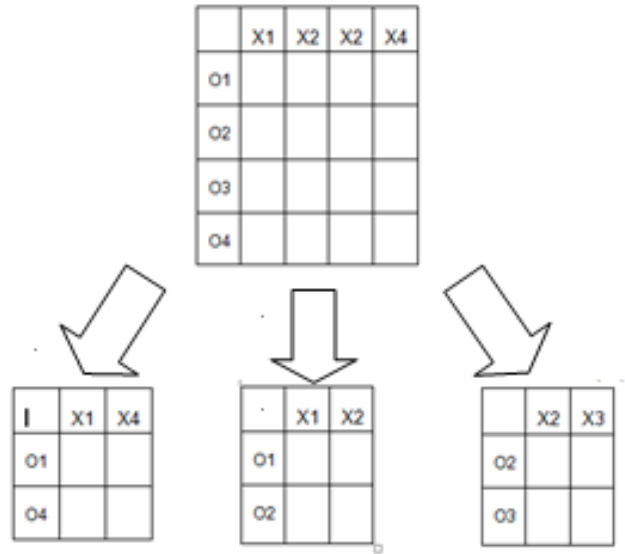

Fig. 3.Original matrix and three submatrices: A (left), B (center) and $\mathrm{C}$ (right)

The process begins by positioning each of the ants that make up the colony in a randomly chosen submatrix. Then each ant creates its own solution, as each one begins to move around the graph. The graph has an associated adjacency matrix where each cell i,j have misclassification to fuse the submatrices i-th and j-th (figure 4).

\begin{tabular}{|l|l|l|l|}
\hline & A & B & C \\
\hline A & Error A & Erro A+B & Error A+C \\
\hline B & Erro A+B & Error B & Erro B+C \\
\hline C & Error A+C & Erro B+C & Error C \\
\hline
\end{tabular}

Fig. 4.Adjacency matrix for the fusion of the submatrices of figure 3, using ACO

In the ACO process, the ants move in the graph. In the case of the sub-matrix fusion problem, the heuristic function used is $\eta_{i j}=1 / d_{i j}$, where dij is the classification error of the sub-matrix $i$ and the sub-matrix $j$, represented in the graph at position $\mathrm{i}, \mathrm{j}$ and the neighborhood $\mathrm{Ni}$ of node $\mathrm{i}$, are the sub-matrices that have not been visited by the ant that is making the movement. After visiting a submatrix, the pheromone values are increased with a step-by-step online update.

This process is repeated by all the ants in the colony, each ant ends when its neighborhood $\mathrm{N}_{\mathrm{i}}=\emptyset$, or when a solution is obtained with a better error than the original. Whenever solutions are obtained, they are evaluated to have stored the path of least error found so far (best overall solution).

Published By:

Blue Eyes Intelligence Engineering DOI: 10.35940/ijeat.D7325.049420

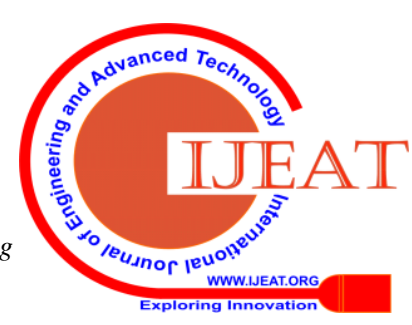


When each ant in the colony found its solution, it passes to the evaporation of the pheromone traces belonging to the best solution found so far. In addition, an update is made of the pheromone traces associated with this solution.

Table- I: Databases used

\begin{tabular}{|c|c|c|c|}
\hline \multirow[b]{2}{*}{ Database } & \multicolumn{3}{|c|}{ Description } \\
\hline & $\begin{array}{c}\text { Attributes } \\
\text { (categorical - } \\
\text { numerical) }\end{array}$ & $\begin{array}{c}\text { Instance } \\
\mathrm{s}\end{array}$ & $\begin{array}{c}\text { Missing } \\
\text { values }\end{array}$ \\
\hline anneal & $29-9$ & 798 & $\mathrm{x}$ \\
\hline autos & $10-16$ & 205 & $\mathrm{x}$ \\
\hline breast-c & $9-0$ & 289 & $\mathrm{x}$ \\
\hline breast-w & $0-9$ & 699 & \\
\hline car & $6-0$ & 1728 & \\
\hline colic & $15-7$ & 368 & $\mathrm{x}$ \\
\hline credit-a & $9-6$ & 690 & $\mathrm{x}$ \\
\hline credit-g & $13-7$ & 1000 & \\
\hline diabetes & $0-8$ & 768 & \\
\hline ecoli & $2-5$ & 336 & \\
\hline glass & $0-8$ & 214 & \\
\hline hayes-roth & $0-5$ & 132 & \\
\hline heart-c & $7-6$ & 303 & $\mathrm{x}$ \\
\hline heart-h & $7-6$ & 294 & $\mathrm{x}$ \\
\hline hepatitis & $13-6$ & 155 & $\mathrm{x}$ \\
\hline iris & $0-4$ & 150 & \\
\hline labor & $6-8$ & 57 & \\
\hline lymph & $15-3$ & 148 & \\
\hline new-thyroid & $5-0$ & 215 & \\
\hline tae & $2-3$ & 151 & \\
\hline tic-tac-toe & $0-9$ & 958 & \\
\hline vehicle & $0-18$ & 946 & \\
\hline vote & $16-0$ & 435 & $\mathrm{x}$ \\
\hline vowel & $3-9$ & 990 & \\
\hline wine & $0-13$ & 178 & $\mathrm{x}$ \\
\hline zOO & $16-1$ & 101 & \\
\hline
\end{tabular}

The entire process explained above is executed until one of the stop conditions is met, which in this case would be as long as the original error of the training matrix was less than the classification error of the merged matrices or there are no more sub-matrices to merge

ACO requires various parameters. In this case the values of alpha $=3$ and rho $=0$ were used [65].

We used several databases from the University of California at Irvine (UCI) repository [66]. The description of the databases used in the experiments is shown in Table I. As can be seen, databases of different nature were used.

The performance of the new fusion strategy, called FIS_ACO (Feature and Instance Selection with ACO fusion) was compared with respect to the TCCS sub-matrix fusion model and with respect to the original classifier, with all features and objects. Three parameters were taken into account: the classifier error, the object retention rate and the feature retention rate. The HEOM proposed by Wilson and Martínez was used as a dissimilarity function [67].

All the experimental results obtained in this work were developed in a computer machine with IntelP5 processor at 3.07 GHz speed, $512 \mathrm{MB}$ of RAM, with Windows XP operating system.

The algorithms were implemented in the C\# language, for which Visual Studio was used in its 2010 version as a development environment. The amount of ants that was used for the FIS_ACO algorithm was 10 ants and the number of iterations was 50.

For the experimental analysis, a 10-fold cross-validation process was used, and the results were averaged. Figures 5 and 6 show the results obtained.

However, to establish whether or not there were significant differences in the performance of the methods, the Wilcoxon test was applied in each of the aspects evaluated (classifier error, object retention rate and feature retention rate). The results of this test are shown in table II. In each case it was taken as a null hypothesis that there were no differences between the algorithms, and as an alternative hypothesis that the FIS_ACO performed better.

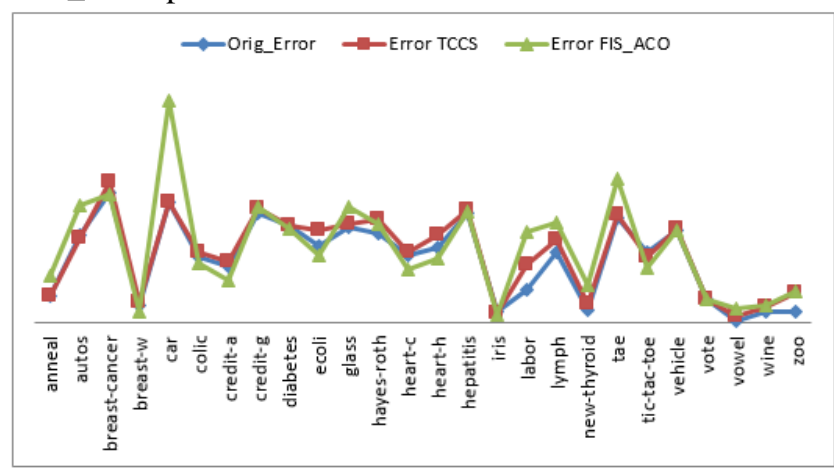

Fig. 5.Results for classifier error

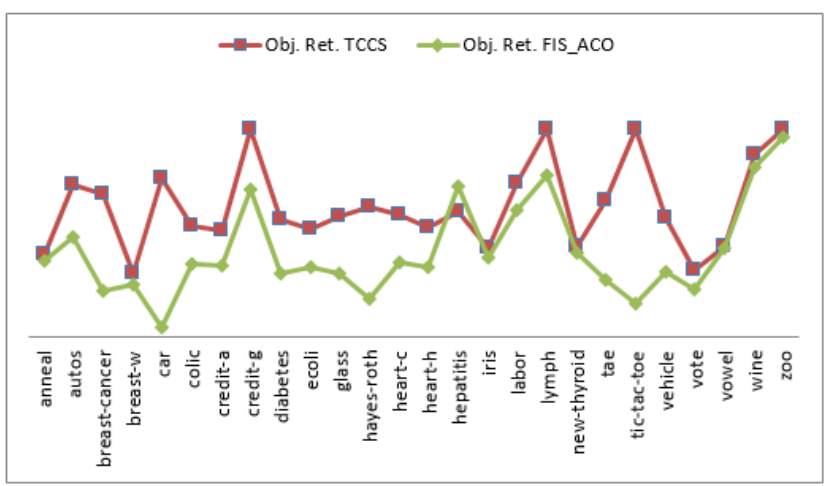

Fig. 6.Results for object retention

Table- II: Results of the Wilcoxon test

\begin{tabular}{|c|c|c|c|}
\multirow{2}{*}{ Pair } & \multicolumn{3}{|c|}{ p-values } \\
\cline { 2 - 4 } & $\begin{array}{c}\text { Classifier } \\
\text { error }\end{array}$ & $\begin{array}{c}\text { Object } \\
\text { retention }\end{array}$ & $\begin{array}{c}\text { Feature } \\
\text { retention }\end{array}$ \\
\hline FIS-ACO vs Original & 0.062 & 0.000 & 0.000 \\
\hline FIS-ACO vs TCCS & 0.675 & 0.000 & 0.144 \\
\hline
\end{tabular}

A 95\% confidence interval was established. Thus, for probability values $\mathrm{p}>0.05$,

Published By:

Blue Eyes Intelligence Engineering

\& Sciences Publication

(C) Copyright: All rights reserved. 
the null hypothesis is not rejected, so there are no significant differences, and for $\mathrm{p}<0.05$ the null hypothesis is rejected, so it is possible to assert that the new FIS_ACO scheme had better performance. The results obtained by the Wilcoxon test showed that the new FIS_ACO scheme has the same error as the algorithms with which it was compared (original classifier and TCCS), but exceeds the TCCS and the original in terms of object retention. These results guarantee the good performance of the proposed new scheme.

\section{CONCLUSION}

In this work, a new submatrix fusion scheme based on Artificial Ant Colonies was introduced. The proposed scheme uses ACO metaheuristics for the first time for submatrix fusion. This scheme includes a pre-processing phase of the training set based on Approximate Minimum Neighborhood Sets for noise filtering. The proposal exceeds those reported in the literature, as it maintains the error of the original classifier, with a smaller amount of objects and features. It follows that the use of combinatorial optimization techniques in the problem of submatrix fusion achieves better results than the use of simple heuristics.

\section{REFERENCES}

1. M. E. Acevedo-Mosqueda, C. Yáñez-Márquez, and I. López-Yáñez, "Alpha-Beta bidirectional associative memories: theory and applications," Neural Processing Letters, vol. 26, pp. 1-40, 2007.

2. E. Guzman, S. Alvarado, O. Pogrebnyak, and C. Yanez, "Image recognition processor based on morphological associative memories," in Electronics, Robotics and Automotive Mechanics Conference (CERMA 2007), 2007, pp. 260-265.

3. C. Yáñez-Márquez, M. E. Cruz-Meza, F. A. Sánchez-Garfias, and I. López-Yáñez, "Using alpha-beta associative memories to learn and recall RGB images," in International Symposium on Neural Networks, 2007, pp. 828-833.

4. E. Guzmán, O. Pogrebnyak, C. Yañez, and L. P. S. Fernandez, "Morphological transform for image compression," EURASIP Journal on advances in signal processing, vol. 2008, p. 426580, 2008.

5. I. J. Rudas, I. Z. Batyrshin, A. H. Zavala, O. C. Nieto, L. Horváth, and L. V. Vargas, "Generators of fuzzy operations for hardware implementation of fuzzy systems," in Mexican International Conference on Artificial Intelligence, 2008, pp. 710-719.

6. I. R. Godínez, I. López-Yánez, and C. Yánez-Márquez, "Classifying patterns in bioinformatics databases by using Alpha-Beta associative memories," in Biomedical Data and Applications, ed: Springer, 2009, pp. 187-210.

7. I. J. Rudas, I. Z. Batyrshin, A. H. Zavala, O. C. Nieto, and L. V. Vargas, "Digital fuzzy parametric conjunctions for hardware implementation of fuzzy systems," in 2009 IEEE International Conference on Computational Cybernetics (ICCC), 2009, pp. 157-166.

8. A. H. Zavala, I. Z. Batyrshin, I. J. Rudas, L. V. Vargas, and O. C. Nieto, "Parametric operations for digital hardware implementation of fuzzy systems," in Mexican International Conference on Artificial Intelligence, 2009, pp. 432-443.

9. A. H. Zavala, O. C. Nieto, I. Batyrshin, and L. V. Vargas, "VLSI Implementation of a Module for Realization of Basic t-norms on Fuzzy Hardware," in 2009 IEEE International Conference on Fuzzy Systems, 2009, pp. 655-659.

10. M. E. Acevedo, C. Yáñez-Márquez, and M. A. Acevedo, "Associative models for storing and retrieving concept lattices," Mathematical Problems in Engineering, vol. 2010, 2010.

11. I. López-Yáñez, A. J. Argüelles-Cruz, O. Camacho-Nieto, and C. Yáñez-Márquez, "Pollutants time-series prediction using the Gamma classifier," International Journal of Computational Intelligence Systems, vol. 4, pp. 680-711, 2011.

12. S. J. Lopez, O. C. Nieto, and J. I. C. Oria, "Non-parametric modeling of uncertain hyperbolic partial differential equations using pseudo-high order sliding mode observers," International Journal of Innovative Computing, Information and Control, vol. 8, pp. 1501-1521, 2012.
13. L. Cleofas-Sánchez, V. García, R. Martín-Félez, R. Valdovinos, J. S Sánchez, and O. Camacho-Nieto, "Hybrid associative memories for imbalanced data classification: an experimental study," in Mexican Conference on Pattern Recognition, 2013, pp. 325-334.

14. C. Yanez-Marquez, I. Lopez-Yanez, O. Camacho-Nieto, and A. J. Arguelles-Cruz, "BDD-based algorithm for the minimum spanning tree in wireless ad-hoc network routing," IEEE Latin America Transactions, vol. 11, pp. 600-601, 2013.

15. A. H. Zavala, I. Z. Batyrshin, O. C. Nieto, and O. Castillo, "Conjunction and disjunction operations for digital fuzzy hardware," Applied Soft Computing, vol. 13, pp. 3248-3258, 2013.

16. M. A. Medina-Pérez, M. García-Borroto, Y. Villuendas-Rey, and J. Ruiz-Shulcloper, "Selecting objects for ALVOT," in Iberoamerican Congress on Pattern Recognition, 2006, pp. 606-613.

17. Y. Villuendas-Rey, M. García-Borroto, and J. Ruiz-Shulcloper, "Selecting features and objects for mixed and incomplete data," in Iberoamerican Congress on Pattern Recognition, 2008, pp. 381-388.

18. M. García-Borroto, Y. Villuendas-Rey, J. A. Carrasco-Ochoa, and J. F. Martínez-Trinidad, "Using maximum similarity graphs to edit nearest neighbor classifiers," in Iberoamerican Congress on Pattern Recognition, 2009, pp. 489-496.

19. M. García-Borroto, Y. Villuendas-Rey, J. A. Carrasco-Ochoa, and J. F Martínez-Trinidad, "Finding small consistent subset for the nearest neighbor classifier based on support graphs," in Iberoamerican Congress on Pattern Recognition, 2009, pp. 465-472.

20. Y. Villuendas-Rey, M. García-Borroto, M. A. Medina-Pérez, and J. Ruiz-Shulcloper, "Simultaneous features and objects selection for Mixed and Incomplete data," in Iberoamerican Congress on Pattern Recognition, 2006, pp. 597-605.

21. P. Moreno-Moreno and C. Yáñez-Márquez, "The new informatics technologies in education debate," in World Summit on Knowledge Society, 2008, pp. 291-296.

22. C. Yáñez-Márquez, I. López-Yáñez, and G. d. l. L. S. Morales, "Analysis and prediction of air quality data with the gamma classifier," in Iberoamerican Congress on Pattern Recognition, 2008, pp. 651-658.

23. Y. Villuendas-Rey, Y. Caballero-Mota, and M. M. García-Lorenzo, "Using rough sets and maximum similarity graphs for nearest prototype classification," in Iberoamerican Congress on Pattern Recognition, 2012, pp. 300-307.

24. Y. Villuendas-Rey, Y. Caballero-Mota, and M. M. García-Lorenzo, "Intelligent feature and instance selection to improve nearest neighbor classifiers," in Mexican International Conference on Artificial Intelligence, 2012, pp. 27-38.

25. Y. Villuendas-Rey, Y. Caballero-Mota, and M. M. García-Lorenzo, "Prototype selection with compact sets and extended rough sets," in Ibero-American Conference on Artificial Intelligence, 2012, pp. 159-168.

26. Y. Villuendas-Rey, C. Rey-Benguría, Y. Caballero-Mota, and M. M. García-Lorenzo, "Nearest prototype classification of special school families based on hierarchical compact sets clustering," in Ibero-American Conference on Artificial Intelligence, 2012, pp. 662-671.

27. Y. Villuendas-Rey, M. M. Garcia-Lorenzo, and R. Bello, "Support Rough Sets for decision-making," in Fourth International Workshop on Knowledge Discovery, Knowledge Management and Decision Support, 2013

28. I. López-Yáñez, L. Sheremetov, and C. Yáñez-Márquez, "A novel associative model for time series data mining," Pattern Recognition Letters, vol. 41, pp. 23-33, 2014.

29. M. D. Lytras, H. Mathkour, H. I. Abdalla, C. Yáñez-Márquez, and P. O. De Pablos, "The Social Media in Academia and EducationResearch R-evolutions and a Paradox: Advanced Next Generation Social Learning Innovation," J. UCS, vol. 20, pp. 1987-1994, 2014.

30. I. Salgado, O. Camacho, C. Yáñez, and I. Chairez, "Proportional derivative fuzzy control supplied with second order sliding mode differentiation," Engineering Applications of Artificial Intelligence, vol. 35, pp. 84-94, 2014.

31. I. Salgado, I. Chairez, O. Camacho, and C. Yañez, "Super-twisting sliding mode differentiation for improving PD controllers performance of second order systems," ISA transactions, vol. 53, pp. 1096-1106, 2014.
Blue Eyes Intelligence Engineering \& Sciences Publication

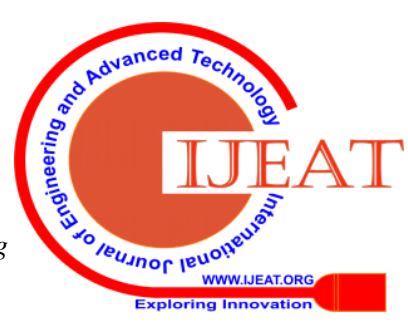


32. Y. Villuendas-Rey and M. M. Garcia-Lorenzo, "Attribute and case selection for nn classifier through rough sets and naturally inspired algorithms," Computación y Sistemas, vol. 18, pp. 295-311, 2014.

33. C. Yáñez-Márquez, M. Aldape-Perez, I. López-Yáñez, and O. Camacho-Nieto, "Emerging computational tools: Impact on engineering education and computer science learning," International Journal of Engineering Education, pp. 533-542, 2014.

34. M. Aldape-Pérez, C. Yáñez-Márquez, O. Camacho-Nieto, I. López-Yáñez, and A.-J. Argüelles-Cruz, "Collaborative learning based on associative models: Application to pattern classification in medical datasets," Computers in Human Behavior, vol. 51, pp. 771-779, 2015.

35. S. Guo-Hua, D. Popov, O. Camacho-Nieto, and D. Shi-Hai, "Shannon information entropies for position-dependent mass Schrödinger problem with a hyperbolic well," Chinese Physics B, vol. 24, p. 100303, 2015

36. I. López-Yáñez, C. Yáñez-Márquez, O. Camacho-Nieto, M. Aldape-Pérez, and A.-J. Argüelles-Cruz, "Collaborative learning in postgraduate level courses," Computers in Human Behavior, vol. 51, pp. 938-944, 2015.

37. A. Ferreira-Santiago, C. Yanez-Marquez, I. Lopez-Yanez, O. Camacho-Nieto, M. Aldape-Perez, and A. J. Arguelles-Cruz, "Enhancing engineering education through link prediction in social networks," International Journal of Engineering Education, pp. 1566-1578, 2016.

38. S. Cerón-Figueroa, I. López-Yáñez, W. Alhalabi, O. Camacho-Nieto, Y. Villuendas-Rey, M. Aldape-Pérez, et al., "Instance-based ontology matching for e-learning material using an associative pattern classifier," Computers in Human Behavior, vol. 69, pp. 218-225, 2017.

39. S. Cerón-Figueroa, I. López-Yáñez, Y. Villuendas-Rey, O Camacho-Nieto, M. Aldape-Pérez, and C. Yáñez-Márquez, "Instance-based ontology matching for open and distance learning materials," The International Review of Research in Open and Distributed Learning, vol. 18, 2017.

40. A. García-Floriano, A. Ferreira-Santiago, C. Yáñez-Márquez, O. Camacho-Nieto, M. Aldape-Pérez, and Y. Villuendas-Rey, "Social Web Content Enhancement in a Distance Learning Environment: Intelligent Metadata Generation for Resources," International Review of Research in Open and Distributed Learning, vol. 18, pp. 161-176, 2017.

41. S. Ortiz-Ángeles, Y. Villuendas-Rey, I. López-Yáñez, O. C. Nieto, and C. Yáñez-Márquez, "Electoral Preferences Prediction of the YouGov Social Network Users Based on Computational Intelligence Algorithms," J. UCS, vol. 23, pp. 304-326, 2017.

42. R. Ramírez-Rubio, M. Aldape-Pérez, C. Yáñez-Márquez, I. López-Yáñez, and O. Camacho-Nieto, "Pattern classification using smallest normalized difference associative memory," Pattern Recognition Letters, vol. 93, pp. 104-112, 2017.

43. I. Salgado, D. Cruz-Ortiz, O. Camacho, and I. Chairez, "Output feedback control of a skid-steered mobile robot based on the super-twisting algorithm," Control Engineering Practice, vol. 58, pp. 193-203, 2017.

44. I. Salgado, C. Yañez, O. Camacho, and I. Chairez, "Adaptive control of discrete-time nonlinear systems by recurrent neural networks in quasi-sliding mode like regime," International Journal of Adaptive Control and Signal Processing, vol. 31, pp. 83-96, 2017.

45. Y. Villuendas-Rey, C. Rey-Benguría, M. Lytras, C. Yáñez-Márquez, and O. Camacho-Nieto, "Simultaneous instance and feature selection for improving prediction in special education data," Program, vol. 51, pp. 278-297, 2017.

46. Y. Villuendas-Rey, C. F. Rey-Benguría, Á. Ferreira-Santiago, O. Camacho-Nieto, and C. Yáñez-Márquez, "The naïve associative classifier (NAC): a novel, simple, transparent, and accurate classification model evaluated on financial data," Neurocomputing, vol. 265, pp. 105-115, 2017.

47. Y. Santiesteban and A. Pons-Porrata, "LEX: A new algorithm to calculate typical testors. ," Mathematics Sciences Journal, vol. 21, 2003.

48. J. A. Antón-Vargas, Y. Villuendas-Rey, C. Yáñez-Márquez, I. López-Yáñez, and O. Camacho-Nieto, "Improving the performance of an associative classifier by Gamma rough sets based instance selection," International Journal of Pattern Recognition and Artificial Intelligence, vol. 32, p. 1860009, 2018.

49. E. Barroso, Y. Villuendas, and C. Yanez, "Bio-inspired algorithms for improving mixed and incomplete data clustering," IEEE Latin America Transactions, vol. 16, pp. 2248-2253, 2018.

50. A. García-Floriano, C. López-Martín, C. Yáñez-Márquez, and A. Abran, "Support vector regression for predicting software enhancement effort," Information and Software Technology, vol. 97, pp. 99-109, 2018.

51. D. González-Patiño, Y. Villuendas-Rey, and A. J. Argüelles-Cruz, "The potential use of bioinspired algorithms applied in the segmentation of mammograms," 2018.

52. J. A. Hernández-Castaño, Y. Villuendas-Rey, O. Camacho-Nieto, and C. Yáñez-Márquez, "Experimental platform for intelligent computing (EPIC)," Computación y Sistemas, vol. 22, pp. 245-253, 2018.

53. Y. O. Serrano-Silva, Y. Villuendas-Rey, and C. Yáñez-Márquez, "Automatic feature weighting for improving financial Decision Support Systems," Decision Support Systems, vol. 107, pp. 78-87, 2018.

54. Y. Villuendas-Rey, M. D. Alanis-Tamez, C. Rey-Benguría, C Yáñez-Márquez, and O. C. Nieto, "Medical Diagnosis of Chronic Diseases Based on a Novel Computational Intelligence Algorithm," $J$. UCS, vol. 24, pp. 775-796, 2018.

55. C. Yáñez-Márquez, I. López-Yáñez, M. Aldape-Pérez, O. Camacho-Nieto, A. J. Argüelles-Cruz, and Y. Villuendas-Rey, "Theoretical Foundations for the Alpha-Beta Associative Memories: 10 Years of Derived Extensions, Models, and Applications," Neural Processing Letters, vol. 48, pp. 811-847, 2018.

56. D. González-Patiño, Y. Villuendas-Rey, A.-J. Argüelles-Cruz, and F. Karray, "A Novel Bio-Inspired Method for Early Diagnosis of Breast Cancer through Mammographic Image Analysis," Applied Sciences, vol. 9, p. 4492, 2019.

57. Y. Villuendas-Rey, J. A. Hernández-Castaño, O. Camacho-Nieto, C. Yáñez-Márquez, and I. López-Yañez, "NACOD: A Naïve Associative Classifier for Online Data," IEEE Access, vol. 7, pp. 117761-117767, 2019.

58. Y. Villuendas-Rey, C. Yáñez-Márquez, J. A. Antón-Vargas, and I. López-Yáñez, "An Extension of the Gamma Associative Classifier for Dealing With Hybrid Data," IEEE Access, vol. 7, pp. 64198-64205 2019.

59. D. E. Goldberg, Genetic Algorithms in Search. University of Alabama: Addison-Wesley Publishing Company, 1998.

60. J. K. a. R. C. Eberhart, "Particle swarm optimization.," in on neural networks, Piscataway, NJ, 1995, pp. 1942-1948.

61. M. D. a. T. Stützle, ACO Algorithms for the Traveling Salesman Problem. EEUU: John Wiley \& Sons, 1999.

62. D. M. a. L. Gambardella, "Ant Colonies for the Traveling Salesman Problem," BioSystems, vol. 43, pp. 73-81, 1997.

63. M. García-Borroto, Y. Villuendas-Rey, M. A. Medina-Pérez, J. Martinez-López, and J. Ruiz-Shulcloper, "Selección y construcción de objetos para el mejoramiento de clasificadores supervisados: un análisis crítico," CENATAV, La Habana, Cuba2008.

64. Y. Villuendas-Rey, "Maximal similarity granular rough sets for mixed and incomplete information systems," Soft Computing, vol. 23, pp. 4617-4631, 2019.

65. M. D. Gambardella, "Ant Colony System: A cooperative learning approach to the traveling salesman problem," IEEE Transactions on Evolutionary Computation, vol. 1, pp. 53-66, 1997.

66. D. Dua and C. Graff. (2019). UCI Machine Learning Repository [http://archive.ics.uci.edu/ml].

67. R. D. Wilson and T. R. Martinez, "Improved Heterogeneous Distance Functions," Journal of Artificial Intelligence Research, vol. 6, pp. 1-34, 1997.

\section{AUTHORS PROFILE}

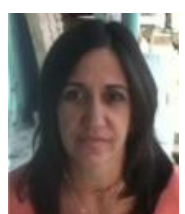

Carmen F. Rey-Benguría acquired her Bachelor degree on Preschooler Pedagogy and Psychology at Hersen State Pedagogical Institute in Saint Petersburg, Russia. Her MSc and Ph.D. (2002 and 2005, respectively) degrees on Pedagogical Sciences were established at Universidad de Oriente, Cuba. Presently, she is with Universidad de Ciego de Ávila, Cuba, as the chief of the Ph.D. program in Educational Sciences of the Educational Center "José Martí". Her investigation interests comprise communication, psychological strategies, artificial intelligence in society and pattern recognition. She had received the Ministry of Education award to the best post-graduate teacher, and the University of Ciego de Ávila award for the best Ph.D. program coordination.

Published By:

Blue Eyes Intelligence Engineering

\& Sciences Publication

(C) Copyright: All rights reserved. 